\title{
SOME FIXED POINTS OF EXPANSION MAPPINGS
}

\author{
H. K. PATHAK \\ Department of Mathematics, \\ Kalyan Mahavidyalaya, \\ Bhilai Nagar (M.P.) 490006, India
}

\section{S. M. KANG}

Department of mathematics, Gyeongsang National University, Chinju 660-701, Korea

\section{J. W. RYU}

Department of mathematics, Dong-A University, Pusan 604-714, Korea

(Received February 1, 1995 and in revised form April 19, 1994)

ABSTRACT. Wang et al. [11] proved some fixed point theorems on expansion mappings, which correspond some contractive mappings. Recently, several authors generalized their results by some ways.

In this paper, we give some fixed point theorems for expansion mappings, which improve the results of some authors.

KEY WORDS AND PHRASES. Expansion mappings and fixed points. 1992 AMS SUBJECT ClASSIFICATION CODE. 54H25.

\section{INTRODUCTION.}

Rhoades [8] summarized contractive mappings of some types and discussed on fixed points. Wang et al. [11] proved some fixed point theorems on expansion mappings, which correspond to some contractive mappings in [8]. Recently, by using functions, Khan et al. [5] generalized the results of [11], and Park and Rhoades [7] proved some fixed point theorems for expansion mappings. Also, Rhoades [9] and Taniguchi [10] generalized the results of [11] for pairs of mappings. Furthermore, Kang [3] and Kang and Rhoades [4] extend the results obtained by Khan et al. [5], Rhoades [9] and Taniguchi [10].

In this paper, we give some fixed point theorems for expansion mappings, which improve the results of Kang [3], Khan et al. [5], Rhoades [9] and Taniguchi [10].

\section{THE MAIN THEOREMS.}

Throughout this paper, following Boyd and Wong [1], let $\mathcal{F}$ be the family of mappings such that for each $\phi \in \mathcal{F}, \phi:[0, \infty) \rightarrow[0, \infty)$ is upper semi-continuous from the right and non-decreasing in each coordinate variable with $\phi(t)<t$ for all $t>0$.

We also need the following Lemma due to Matkoski [6] in the proof of our main theorems. 
LEMMA. If $\phi(t)<t$ for every $t>0$, then $\lim _{n \rightarrow \infty} \phi^{n}(t)=0$, where $\phi^{n}(t)$ denotes the composition of $\phi(t)$ with n-trmes.

Now, we prove some common fixed point theorems.

THEOREM 2.1. Let $S$ and $T$ be mappings from a metric space $(X, d)$ into itself such that $S(X) \subseteq S^{2}(X), S(X) \subseteq T S(X)$ and $S(X)$ is complete. Suppose that there exists $\phi \in \mathcal{F}$ such that for each $x, y$ in $X$, at least one of the following conditions holds:

$$
\begin{aligned}
& \phi\left(d\left(S^{2} x, T S y\right)\right) \geq d(S x, S y) . \\
& \phi\left(d\left(S^{2} x, T S y\right)\right) \geq \frac{1}{2}[d(S x, S y)+d(T S y, S y)] . \\
& \phi\left(d\left(S^{2} x, T S y\right)\right) \geq \frac{1}{2}\left[d\left(S x, S^{2} x\right)+d(S x, S y)\right] . \\
& \phi\left(d\left(S^{2} x, T S y\right)\right) \geq \frac{1}{3}\left[d\left(S x, S^{2} x\right)+d(T S y, S y)+d(S x, S y)\right] .
\end{aligned}
$$

Then either $S$ or $T$ has a fixed point, or $S$ and $T$ have a common fixed point.

PROOF. Let $x_{0}$ be an arbitrary point $X$. Since $S(X) \subseteq S^{2}(X)$ and $S(X) \subseteq T S(X)$, we have for ${ }^{\prime} x_{0} \in X$., there exists a point $x_{1}$ in $X$ such that $S^{2} x_{1}=S x_{0}=y_{0}$, say, and for this point $x_{1}$, there exists a point $x_{2}$ in $X$ such that $T S x_{2}=S x_{1}=y_{1}$, say. Inductively, we can define a sequence $\left\{y_{n}\right\}$ in $S(X)$ such that

$$
S^{2} x_{2 n+1}=S x_{2 n}=y_{2 n} \text { and } T S x_{2 n+2}=S x_{2 n+1}=y_{2 n+1} .
$$

It is easy to show that, for earh of the inequalities $(2.1) \sim(2.4)$, that we have $\phi\left(d\left(y_{2 n}, y_{2 n+1}\right)\right) \geq$ $d\left(y_{2 n+1}, y_{2 n+2}\right)$. Then one can show that $\phi\left(d\left(y_{2 n+1}, y_{2 n+2}\right)\right) \geq d\left(y_{2 n+2}, y_{2 n+3}\right)$, hence for arbitrary $n$,

$$
\phi\left(d\left(y_{n}, y_{n+1}\right)\right) \geq d\left(y_{n+1}, y_{n+2}\right) .
$$

Now, if $y_{2 n}=y_{2 n+1}$ for any $n$, one has that $y_{2 n}$ is a fixed point of $S$ from the definition $\left\{y_{n}\right\}$. It then follows that, also, $y_{2 n+1}=y_{2 n+2}$, which implies that $\left\{y_{2 n}\right\}$ is also a fixed point of $T$.

For an arbitrary $n$, we have

$$
d\left(y_{n}, y_{n+1}\right) \leq \phi\left(d\left(y_{n-1}, y_{n}\right)\right) \leq \cdots \leq \phi^{n}\left(d\left(y_{0}, y_{1}\right)\right)
$$

By Lemma, $\lim _{n \rightarrow \infty} d\left(y_{n}, y_{n+1}\right)=0$.

Now, using the technique of Kang [4], one would prove that $\left\{y_{n}\right\}$ a Cauchy sequence and it converges to some point $y$ in $S(X)$. Consequently, the subsequences $\left\{y_{2 n}\right\},\left\{y_{2 n+1}\right\}$ and $\left\{y_{2 n+2}\right\}$ converge to $y$. Let $y=S^{2} u$ and $y=T S v$ for some $u$ and $v$ in $X$, respectively. From inequalities (2.1) (2.4), it follows that at least one of the following inequalities must be true for an infinite number of values of $n$ :

$$
\begin{aligned}
& \phi\left(d\left(y_{2 n}, y\right)\right) \geq d\left(S x_{2 n+1}, S v\right) \\
& \phi\left(d\left(y_{2 n}, y\right)\right) \geq \frac{1}{2}\left[d\left(S x_{2 n+1}, S v\right)+d(T S v, S v)\right] \\
& \phi\left(d\left(y_{2 n}, y\right)\right) \geq \frac{1}{2}\left[d\left(S x_{2 n+1}, S^{2} x_{2 n+1}\right)+d\left(S x_{2 n+1}, S v\right)\right] \\
& \phi\left(d\left(y_{2 n}, y\right)\right) \geq \frac{1}{3}\left[d\left(S x_{2 n+1}, S^{2} x_{2 n+1}\right)+d(T S v, S v)+d\left(S x_{2 n+1}, S v\right)\right]
\end{aligned}
$$


Taking the limit as $n \rightarrow \infty$ in each case yields $y=S v$. A similar argument applies to proving that $y=S u$. Therefore, $y$ is a common fixed point of $S$ and $T$. This completes the proof.

THEOREM 2.2. Let $S$ and $T$ be continuous mappings from a metric space $(X, d)$ into atself such that $S(X) \subseteq S^{2}(X), S(X) \subseteq T S(X)$ and $S(X)$ is complete. Suppose that there exists $\phi \in \mathcal{F}$ such that

$$
\phi\left(d\left(S^{2} x, T S y\right)\right) \geq \min \left\{d\left(S x, S^{2} x\right), d(T S y, S y), d(S x, S y)\right\}
$$

for all $x, y$ in $X$.

Then $S$ or $T$ has a fixed point or $S$ and $T$ have a common fixed point.

PROOF. Define a sequence $\left\{y_{n}\right\}$ as in Theorem 2.1. If $y_{n}=y_{n+1}$ for any $n$, then $S$ or $T$ has a fixed point.

It is easy to show that, for each of the inequality (2.5), that we have $\phi\left(d\left(y_{2 n}, y_{2 n+1}\right)\right) \geq$ $d\left(y_{2 n+1}, y_{2 n+2}\right)$. Then one can show that $\phi\left(d\left(y_{2 n+1}, y_{2 n+2}\right)\right) \geq d\left(y_{2 n+2}, y_{2 n+3}\right)$, hence for arbitrary $n$,

$$
\phi\left(d\left(y_{n}, y_{n+1}\right)\right) \geq d\left(y_{n+1}, y_{n+2}\right)
$$

For any $m<n$,

$$
\begin{aligned}
d\left(y_{m}, y_{n}\right) & \leq d\left(y_{m}, y_{m+1}\right)+d\left(y_{m+1}, y_{n}\right) \\
& \leq d\left(y_{m}, y_{m+1}\right)+d\left(y_{m+1}, y_{m+2}\right)+\cdots+d\left(y_{n-1}, y_{n}\right) \\
& \leq \phi^{m}\left(d\left(y_{0}, y_{1}\right)\right)+\cdots+\phi^{n-1}\left(d\left(y_{0}, y_{1}\right)\right) .
\end{aligned}
$$

Hence, it follows that $\left\{y_{n}\right\}$ is a Cauchy sequence and it converges to some point $y$ in $S(X)$. Consequently, $\left\{y_{2 n}\right\},\left\{y_{2 n+1}\right\}$ and $\left\{y_{2 n+2}\right\}$ converge to $y$. By the continuity of $S$ and $T$,

$$
S^{2} x_{2 n+1}=S y_{2 n+1}=y_{2 n} \rightarrow S y \text { and } T S x_{2 n+2}=T y_{2 n+2}=y_{2 n+1} \rightarrow T y \text { as } n \rightarrow \infty .
$$

Thus, $S$ and $T$ have a common fixed point.

COROLLARY 2.3. (1) Let $S$ and $T$ be mappings from a metric space $(X, d)$ into itself such that $S(X) \subseteq S^{2}(X), S(X) \subseteq T S(X)$ and $S(X)$ is complete. Suppose that there exists real numbers $h>1$ such that for each $x, y$ in $X$, at least one of the following conditions holds:

$$
\begin{aligned}
d\left(S^{2} x, T S y\right) & \geq h d(S x, S y) \\
d\left(S^{2} x, T S y\right) & \geq \frac{h}{2}[d(S x, S y)+d(T S y, S y)] . \\
d\left(S^{2} x, T S y\right) & \geq \frac{h}{2}\left[d\left(S x, S^{2} x\right)+d(S x, S y)\right] . \\
d\left(S^{2} x, T S y\right) & \geq \frac{h}{3}\left[d\left(S x, S^{2} x\right)+d(T S y, S y)+d(S x, S y)\right]
\end{aligned}
$$

Then either $S$ or $T$ has a fixed point, or $S$ and $T$ have a common fixed point.

(2) Let $S$ and $T$ be continuous mappings from a metric space $(X, d)$ into itself such that $S(X) \subseteq$ $S^{2}(X), S(X) \subseteq T S(X)$ and $S(X)$ is complete. Suppose that there exists $h>1$ such that

$$
d\left(S^{2} x, T S y\right) \geq h \min \left\{d\left(S x, S^{2} x\right), d(T S y, S y), d(S x, S y)\right\}
$$

for all $x, y$ in $X$.

Then $S$ or $T$ has a fixed point or $S$ and $T$ have a common fixed point. 
PROOF. For $\phi \in \mathcal{F}$, we define $\phi:[0, \infty) \rightarrow[0, \infty)$ by $\phi(t)=\frac{1}{h}(t)$, where $h>1$. From Theorem 2.1 and 2.2 , we obtain (1) and (2), respectively.

THEOREM 2.4. Let $S$ and $T$ be mappings from a metric space $(X, d)$ into itself such that $S(X) \subseteq S^{2}(X), S(X) \subseteq T S(X)$ and $S(X)$ is complete. Suppose that there exists non-negative real numbers $\alpha<1, \beta<1$ and $\gamma(\alpha+\beta+\gamma>1)$ such that

$$
d\left(S^{2} x, T S y\right) \geq \alpha d\left(S x, S^{2} x\right)+\beta d(T S y, S y)+\gamma d(S x, S y)
$$

for all $x, y$ in $X$.

Then $S$ and $T$ have a common fixed point.

PROOF. Define a sequence $\left\{y_{n}\right\}$ as in Theorem 2.1. Suppose that $y_{2 n}=y_{2 n+1}$ for some $n$. Then

$$
\begin{aligned}
d\left(y_{2 n}, y_{2 n+1}\right)= & d\left(S^{2} x_{2 n+1}, T S x_{2 n+2}\right) \\
\geq & \alpha d\left(S x_{2 n+1}, S^{2} x_{2 n+1}\right)+\beta d\left(T S x_{2 n+2}, S x_{2 n+2}\right) \\
& \quad+\gamma d\left(S x_{2 n+1}, S x_{2 n+2}\right) \\
= & \alpha d\left(y_{2 n}, y_{2 n+1}\right)+\beta d\left(y_{2 n+1}, y_{2 n+2}\right)+\gamma d\left(y_{2 n+1}, y_{2 n+2}\right),
\end{aligned}
$$

that is, $d\left(y_{2 n}, y_{2 n+1}\right) \geq\left(\frac{\beta+\gamma}{1-\alpha}\right) d\left(y_{2 n+1}, y_{2 n+2}\right)$, which says that $y_{2 n+1}=y_{2 n+2}$ since $\beta+\gamma \neq 0$. Thus, $y_{2 n}$ is a common fixed point of $S$ and $T$. Similarly, $y_{2 n+1}=y_{2 n+2}$ gives that $y_{2 n+1}$ is a common fixed point of $S$ and $T$.

Now, suppose that $y_{n} \neq y_{n+1}$ for each $n$. Then

$$
\begin{aligned}
d\left(y_{2 n}, y_{2 n+1}\right) & =d\left(S^{2} x_{2 n+1}, T S x_{2 n+2}\right) \\
& \geq \alpha d\left(y_{2 n}, y_{2 n+1}\right)+\beta d\left(y_{2 n+1}, y_{2 n+2}\right)+\gamma d\left(y_{2 n+1}, y_{2 n+2}\right) .
\end{aligned}
$$

Thus, we have

$$
d\left(y_{2 n+1}, y_{2 n+2}\right) \leq p_{1} d\left(y_{2 n}, y_{2 n+1}\right), \quad \text { where } p_{1}=\frac{1-\alpha}{\beta+\gamma}<1
$$

Similarly, we have

$$
d\left(y_{2 n+2}, y_{2 n+3}\right) \leq p_{2} d\left(y_{2 n+1}, y_{2 n+2}\right), \quad \text { where } p_{2}=\frac{1-\beta}{\alpha+\gamma}<1
$$

Putting $p=\max \left\{p_{1}, p_{2}\right\}$, we have

$$
d\left(y_{n}, y_{n+1}\right) \leq p d\left(y_{n-1}, y_{n}\right)
$$

Since $p<1$, by Lemma of Jungck [2], $\left\{y_{n}\right\}$ is a Cauchy sequence and it converges to some point $y$ in $S(X)$. Consequently, the subsequences $\left\{y_{2 n}\right\},\left\{y_{2 n+1}\right\}$ and $\left\{y_{2 n+2}\right\}$ converge to $y$. Let $y=S^{2} u$ and $y=T S v$ for some $u$ and $v$ in $X$, respectively. Then

$$
d\left(y_{2 n}, y\right)=d\left(S^{2} x_{2 n+1}, T S v\right) .
$$

Taking the limit as $n \rightarrow \infty$, we have $0 \geq(\beta+\gamma) d(y, S v)$, so that $y=S v$. Similarly, $y=S u$. Therefore, $S$ and $T$ have a common fixed point.

REMARK. Our results improve several results of Kang [3], Khan et al. [5], Rhoades [9] and Taniguchi [10]. Furthermore, we have used non-surjective mappings. 


\section{REFERENCES}

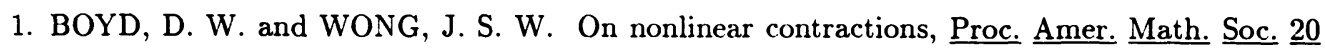
(1969), 458-464.

2. JUNGCK, G. Commuting maps and fixed points, Amer. Math. Monthly $\underline{83}$ (1976), 261-263.

3. KANG, S. M. Fixed points for expansion mappings, Math. Japonica 38 (1993), 713-717.

4. KANG, S. M. and RHOADES, B. E. Fixed points for four mappings, Math. Japonica $\underline{37}$ (1992), 1053-1059.

5. KHAN, M. A., KHAN, M. S. and SESSA, S. Some theorems on expansion mappings and their fixed points, Demonstratio Math. 19 (1986), 673-6s3.

6. MATKOWSKI, J. Fixed point theorems for mappings with contractive iterate at a point, Proc. Math. Soc. 62 (1977), 344-348.

7. PARK, S. and RHOADES, B. E. Some fixed point theorems for expansion mappings, Math. Japonica 33 (1988), 129-132.

8. RHOADES, B. E. A comparison of various definitions of contractive mappings, Trans. Amer. Math. Soc. 226 (1977), 257-290.

9. RHOADES, B. E. Some fixed point theorems for pairs of mappings, Jñānābha 15 (1985), 151-156.

10. TANIGUCHI, T. Common fixed point theorems on expansion type mappings on complete metric spaces, Math. Japonica $\underline{34}$ (1989), 139-142.

11. WANG, S. Z., LI, B. Y., GAO, Z. M. and ISÉKI, K. Some fixed point theorems on expansion mappings, Math. Japonica $\underline{29}$ (1984), 631-636. 


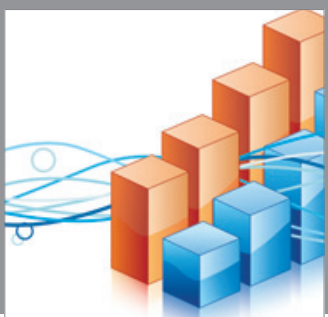

Advances in

Operations Research

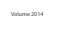

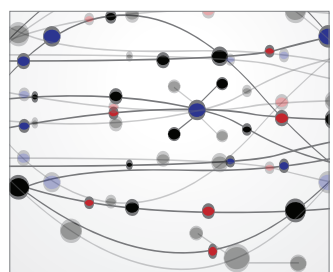

\section{The Scientific} World Journal
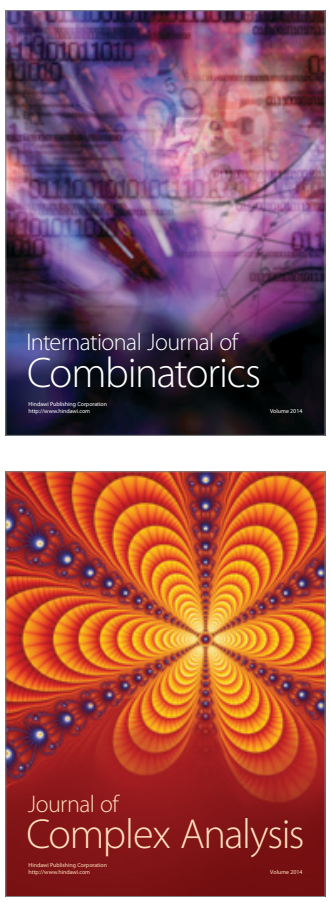

International Journal of

Mathematics and

Mathematical

Sciences
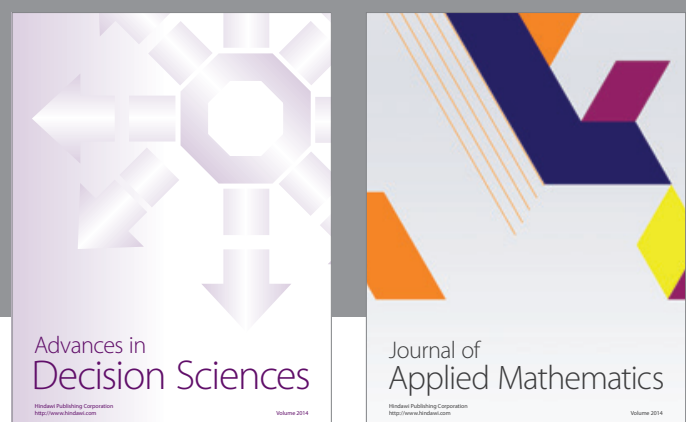

Journal of

Applied Mathematics
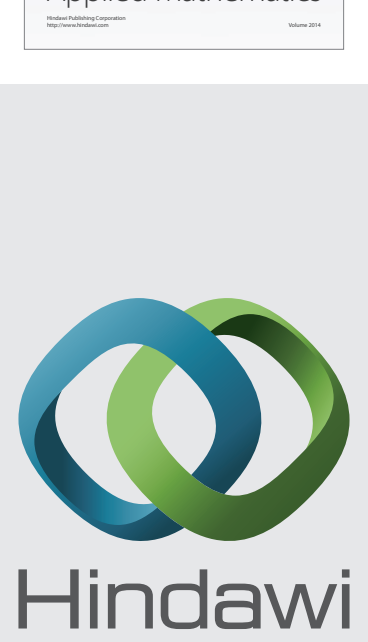

Submit your manuscripts at http://www.hindawi.com
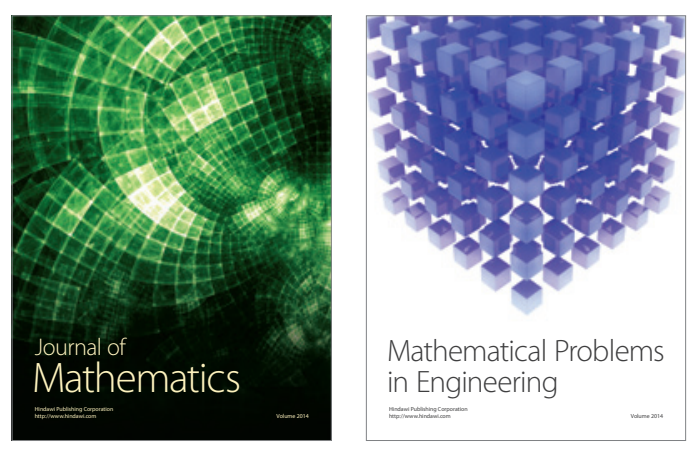

Mathematical Problems in Engineering
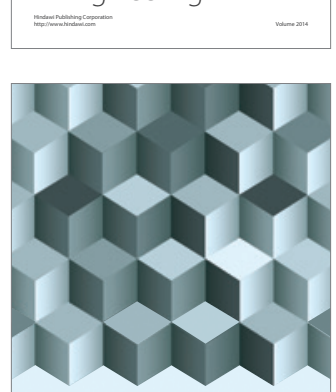

Journal of

Function Spaces
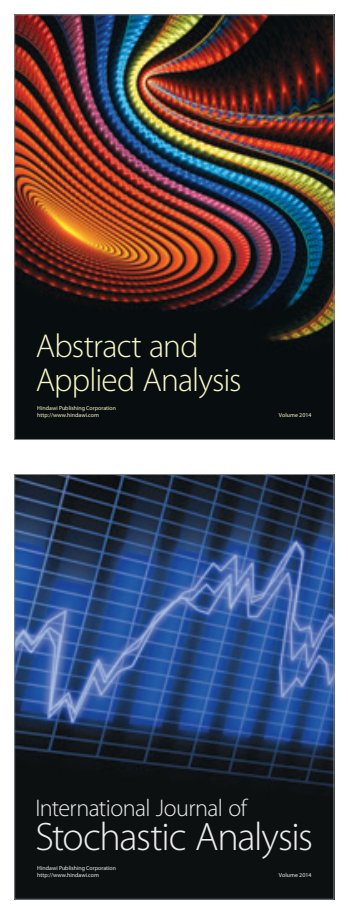

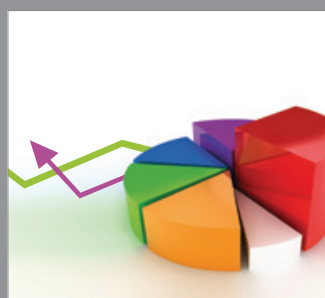

ournal of

Probability and Statistics

Promensencen
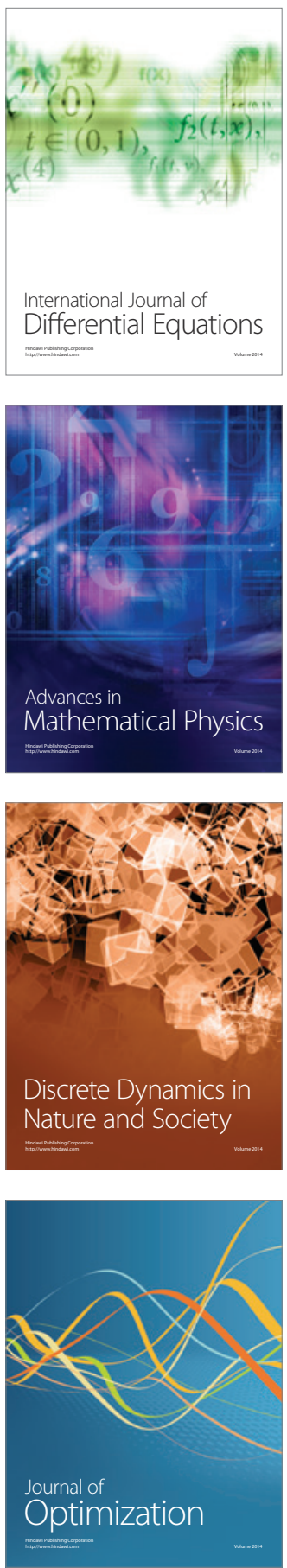